\title{
Exploring small area demand for grocery retailers in tourist areas
}

\author{
ANDY NEWING \\ At time of writing: Centre for Spatial Analysis and Policy, School of Geography, Univer- \\ sity of Leeds, UK. Current: Faculty of Engineering and the Environment, University of \\ Southampton, Highfield, Southampton S017 1BJ, UK.E-mail: a.newing@soton.ac.uk. \\ (Corresponding author.) \\ GRAHAM CLARKe \\ School of Geography, University of Leeds, Leeds LS2 9JT, UK. \\ MARTIN ClaRKe \\ School of Geography, University of Leeds, Leeds LS2 9JT, UK.
}

\begin{abstract}
This paper uses data from a major loyalty card scheme to draw insights about the characteristics of grocery expenditure by tourists. The authors explore the volume, value and composition of storebased visitor expenditure using consumer data from the loyalty card scheme. They focus on grocery spending at selected stores in Cornwall, a popular tourist destination in South West England. The loyalty card data provide a valuable source rarely available for academic investigations. The authors are able to analyse visitor spend by socio-economic and geodemographic characteristics, drawing a range of comparisons with residential demand from within the store catchment areas. They demonstrate that visitor grocery expenditure is complex and varies by store, destination and type of customer. The paper presents evidence to suggest that the current approaches used to estimate sales uplift and local-level economic impact from visitor demand are unable to account for the complexities of this form of expenditure. Based on these insights, the authors recommend that sophisticated modelling is employed to estimate the impact of visitor expenditure.
\end{abstract}

Keywords: visitor expenditure; loyalty card data; grocery retail; economic impact; Cornwall

This research is supported by an ESRC CASE Award (2010-2013) as part of RIBEN. Data have been provided by a collaborating retailer who guided the initial selection of study stores, but who played no other part in the research or preparation of this paper. 
The UK tourism sector is experiencing a period of growth as increasing numbers of domestic holidaymakers are enjoying breaks within the UK. Visit Britain (2010) notes that the number of family holidays taken in the UK rose by $33 \%$ in 2009 , compared to the previous summer, with increases in the use of self-catering accommodation (in the form of rented cottages, apartments, static caravans and lodges) accounting for much of this growth. Self-catering accommodation generates considerable local-level visitor expenditure, principally on food and drink, with self-catering visitors demonstrating a high propensity to eat out or to use catering facilities provided within their accommodation. These visitors source supplies from local stores and generate seasonal demand uplift in a range of local businesses. Many large self-catering accommodation sites benefit from an on-site convenience store but visitors may also make use of stores predominantly designed to meet the needs of local residents, such as supermarkets and other grocery stores. As such, these stores may make up an important component of the services provided for visitors within tourist resorts (Huse et al, 1998; Dudding and Ryan, 2000; Wilton, 2004; Timothy, 2005).

Visitor expenditure may make up a significant proportion of these retailers' revenue at certain times of year, thus supporting the provision of retail services, infrastructure and employment that would not be viable based solely on local residential demand (Dudding and Ryan, 2000). Evidence from some existing stores highlights the potential seasonal demand uplift. For example, Tesco has taken temporary steps to meet seasonal visitor demand fluctuations at its store in the Cornish resort of Padstow. Store capacity, stock and staffing levels are increased during the summer months to cope with visitor demand uplift through the addition of temporary sales floorspace in a marquee in the store car park (Maguire, 2010). The store thus struggles to meet the needs of customers and manage stock and staffing levels during the summer and requires additional floorspace to ease congestion in-store.

Visitor demand of this nature represents a growing opportunity for retailers, but little is actually known about the value of visitor spend at a local level, especially within sectors of the economy, such as grocery retail. As such, firms and local development authorities may be making decisions about service provision with little knowledge of the local-level impact of visitor spend (Jones and Munday, 2009). This form of visitor expenditure plays an important role in local and regional economies, yet is often underestimated or overlooked when considering the local economic impact of visitor spend, or when making location-based decisions about service provision and retail store location. Visitor spend on groceries therefore represents an under-researched area in the tourism sector and in store location planning.

This paper considers tourist resorts in Cornwall, South West England. Tourism is recognized as being one of Cornwall's most valuable industries, supporting recent improvements in infrastructure and service provision (Cornwall Single Issue Panel, 2004), such that the resorts of Newquay, Bude, Padstow and St Ives benefit from retail and service provision that exceeds the usual expectations for centres of their size, largely driven by visitor demand. Newing et al (2012) explored the sales uplift driven by visitor demand at grocery stores in Cornwall using sales and customer data supplied by a major UK grocery retailer. Selected stores were found to demonstrate a pronounced seasonal trade 
pattern driven by visitor demand and the study highlighted the fact that the investigation of seasonal visitor sales is far more complex than the analysis of other forms of demand. In particular the following was noted.

- Visitor spend in grocery stores is not easily identifiable since the stores predominantly cater for the needs of local residents and tourist spend is not explicitly recorded.

- The sales uplift demonstrated a complex seasonal pattern with the volume and value of visitor expenditure fluctuating significantly during the tourist season.

- The exact nature of the sales uplift varied on a store by store basis with some smaller stores generating over half their weekly revenue from visitors at certain times of year.

- Visitor expenditure tends to be spatially and temporally clustered far more than residential demand, with large numbers of visitors existing around key accommodation sites or principal attractions at certain times of year.

- Visitor demand demonstrated a complex spatial pattern with visitor expenditure being attributable to consumers from a range of locations across the UK, thus diverting trade from their usual home stores.

Estimating revenue for proposed new stores is an important role for location planning teams working within major retailers. Predictive site location analysis often makes use of a well-developed suite of modelling tools to estimate store revenue by modelling the interactions between the underlying residential demand and the store network, predicting revenue flows from residential locations to competing stores. Nonetheless, visitor demand is often handled crudely within this revenue estimation process and tends not to form part of the modelling itself. Instead, predicted revenue is often multiplied by an arbitrary factor to account for visitor demand. Recent planning applications in popular tourist resorts within the UK have been accompanied by retail assessments that increase residential demand by $15-30 \%$ to account for visitor expenditure (API, $2010,2011,2012$ ). This approach takes no account of the nature of visitor demand and instead assumes that visitor expenditure is directly proportional to residential demand.

In this paper we explore the characteristics of visitors and draw comparisons with residential demand in grocery stores, outlining clear differences in the nature of visitor and residential demand. This suggests that crude location-based decision making which simply factors up from residential expenditure is not able to account adequately for the consumption habits of visitors. In this paper we demonstrate that in areas where there is likely to be significant visitor demand, location decision making for retail stores or other forms of service provision needs to be able to incorporate small area visitor expenditure by using sophisticated spatial modelling techniques, in order to incorporate fully the local economic impact of seasonal visitor spend. We begin by outlining the stores and dataset used, before exploring visitor characteristics and expenditure in subsequent sections.

\section{Study area and loyalty card dataset}

This research benefits from access to consumer level data from a customer loyalty card scheme operated by a major retailer, which affords a unique 
opportunity to identify the grocery consumption habits associated with individual customers while away from home and to link these habits to their geodemographic characteristics and socio-economic status. Many studies of visitor spend or visitor characteristics take place at an aggregate level (considering all forms of expenditure) (Craggs and Schofield, 2009), consider only a subset of visitors (such as Downward and Lumsdon (2000) who consider only day visitors within one destination; or Algere and Magdalena (2010) who consider only repeat visitors) or focus explicitly on visitor spend associated with particular short-term events (Young et al, 2010; Barquet et al, 2011; Bracalente et al, 2011). There are consequently very few studies that explicitly consider destination level spend on individual categories such as groceries (for one example that does include grocery shopping see Downward and Lumsdon (2003)).

Nonetheless, spending categories such as 'food and drink' are used frequently within destination specific visitor surveys (often referred to as 'destination benchmarking'), yet are predominantly concerned with eating out, such that spending on food and drink purchased from grocery stores is not uniquely identifiable. Using loyalty card data, therefore, allows us to identify customerlevel visitor spend in grocery stores without the need for surveys or participant recall. We are able to draw a series of comparisons between visitor spend and residential consumption in the study area, and with visitors' usual consumption at home, including their pre-trip spend. Surveys of tourist expenditure commonly overlook such spend.

As with Newing et al (2012) Cornwall is used as a study area as it is one of the most popular destinations for domestic tourism within the UK (South West Tourism, 2010; Visit Cornwall, 2010). Four stores are used for this analysis, although the fascia and location are not stated in order to preserve the confidentiality of store and company trading information. The stores are the same as those used in Newing et al (2012) and represent a real opportunity to explore the impact of highly seasonal self-catering visits on food and drink

\begin{tabular}{|c|c|c|c|c|}
\hline Store & Size & Location & Attributes & $\begin{array}{c}\text { Proportion of } \\
\text { loyalty card spend } \\
\text { originating outside } \\
\text { the store trade area } \\
\text { (August 2010) }\end{array}$ \\
\hline $\begin{array}{l}\text { Coastal Resort } \\
\text { Store X }\end{array}$ & $\begin{array}{l}\text { Mid-sized } \\
\text { supermarket }\end{array}$ & $\begin{array}{l}\text { Popular Cornish } \\
\text { coastal resort }\end{array}$ & & $48 \%$ \\
\hline $\begin{array}{l}\text { Coastal Resort } \\
\text { Store Y }\end{array}$ & $\begin{array}{l}\text { Small } \\
\text { supermarket }\end{array}$ & $\begin{array}{l}\text { Popular Cornish } \\
\text { coastal resort }\end{array}$ & & $60 \%$ \\
\hline $\begin{array}{l}\text { Non-Coastal } \\
\text { Store A }\end{array}$ & $\begin{array}{l}\text { Mid-sized } \\
\text { supermarket }\end{array}$ & $\begin{array}{l}\text { Major town or } \\
\text { city in Cornwall }\end{array}$ & $\begin{array}{l}\text { Within easy reach } \\
\text { of a principal } \\
\text { transport link }\end{array}$ & $29 \%$ \\
\hline $\begin{array}{l}\text { Non-Coastal } \\
\text { Store B }\end{array}$ & $\begin{array}{l}\text { Large } \\
\text { supermarket }\end{array}$ & $\begin{array}{l}\text { Major town or } \\
\text { city in Cornwall }\end{array}$ & $\begin{array}{l}\text { Within easy reach } \\
\text { of a principal } \\
\text { transport link }\end{array}$ & $18 \%$ \\
\hline
\end{tabular}


expenditure using comprehensive data from a major loyalty card scheme. In particular 'Coastal Resort Store Y' was found to attract just under two-thirds of its revenue (from transactions involving loyalty cards) from customers thought to represent visitors, and experiences considerable seasonal variation in its sales revenue, staff requirements and stock levels. The stores and their characteristics are outlined in Table 1.

From our four stores of interest (Table 1) data for up to 14 trading weeks in 2010 are available, representing different points in the tourist season (including the peak school summer holidays and Easter alongside weeks in the low and fringe season). The analysis is based on around 500,000 loyalty card transactions, representing over 100,000 unique customers. These transactions represent just over $50 \%$ of in-store spend during the study weeks, with the remaining spend not being attributed to a loyalty card and thus not included in our study. Each transaction involving a loyalty card can be attributed to the card holder via a unique ID number and linked to attribute information provided at the time of registration within the scheme. For the purpose of this study the transaction value, alongside the card holders' home postcode, has been extracted for all recorded loyalty card transactions in these four stores during the weeks of interest. The home postcode allows each customer to be categorized based on his or her home address.

The flowchart and schematic in Figure 1 outline the loyalty card data used in this paper and highlight that loyalty card trade has then been subdivided into three groups based on customer spatial origin. Local residents are those customers using a loyalty card registered to a home postcode falling within the trade area of the store in which the transaction took place. The trade areas have been defined by our collaborating retailer and are based on their in-house market share analysis using loyalty card data at a census output area (OA) level. An OA is the lowest level of aggregation for dissemination of census and administrative data in the UK, representing an average of 124 households (Vickers and Rees, 2006). External trade includes all customers using a loyalty card registered to a home postcode falling outside the trade area for the store in which the transaction took place. They have been further divided into two subcategories. First, overnight visitors are those customers using a loyalty card registered to a home postcode that is over 61 miles from the store in which the transaction took place. A distance of 61 miles was chosen as the threshold to identify visitors staying overnight since the England Leisure Visits Survey (ELVS) identifies that for coastal resorts, day trip visitors had, on average, travelled 61 miles from home (Natural England, 2005, p 21). All visitors originating from a distance greater than 61 miles from the store are therefore more likely to be staying overnight in the area. It is these customers that are of greatest interest to this paper, since visitors staying overnight are likely to demonstrate higher overall expenditure on food and drink. Second, local nonresidential trade therefore covers those customers using a loyalty card registered to a home postcode falling outside the trade area, but within a distance of 61 miles from the store in which the transaction took place and thus not considered to be overnight visitors. This group of consumers is likely to include tourist day visitors, and also a number of non-leisure visitors, such as people living outside the store catchment but visiting the store during non-leisure trips related to other forms of personal mobility, such as work or education. Analysis 


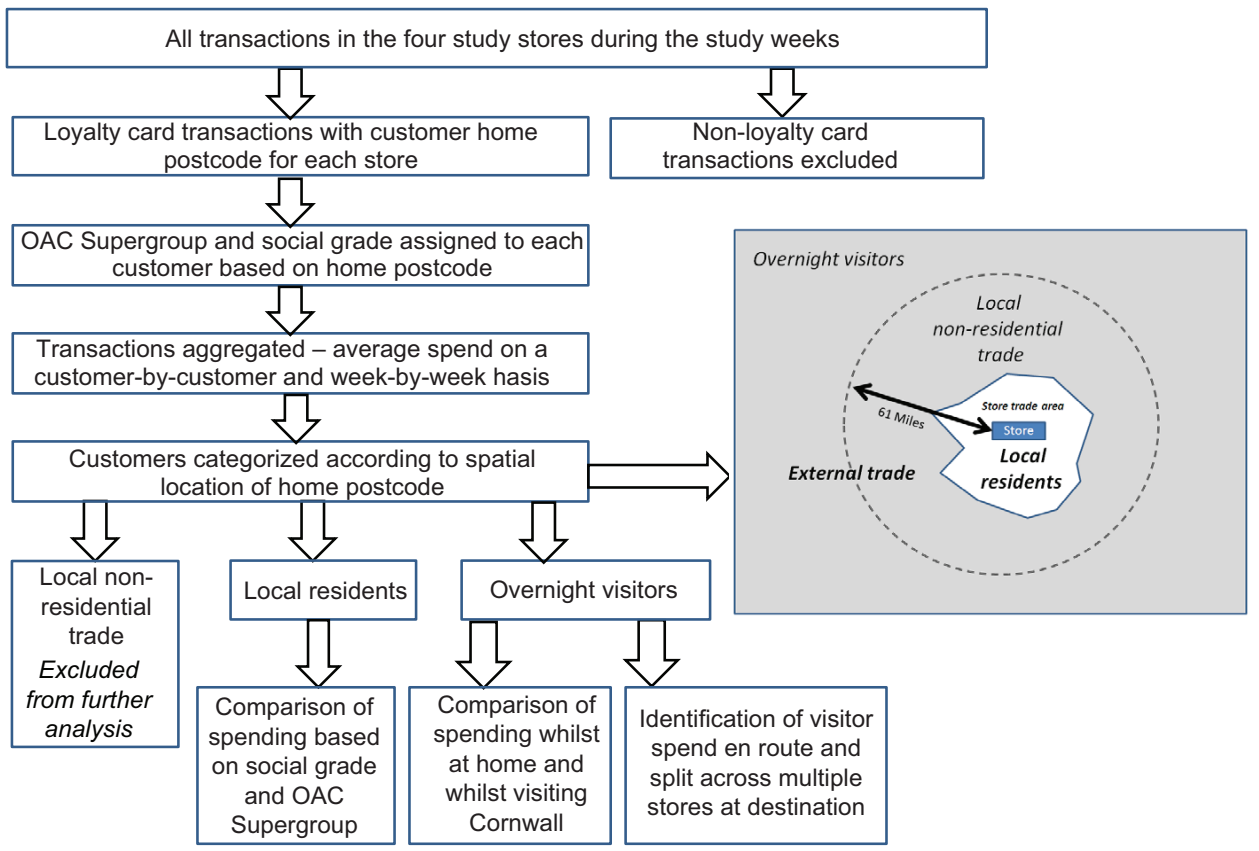

Figure 1. Dataset used for analysis.

has demonstrated that this group exhibits characteristics and expenditure similar to those of local residents and it has not been possible to extract leisure day visitors from this diverse group of customers. As it has not been possible to distinguish the exact make-up of this group, these customers will not be considered further in this paper, but it is hoped to be able to explore this group further in subsequent research.

In order to be able to draw meaningful comparisons between these different groups of consumers, transactions have been aggregated on a customer-bycustomer and week-by-week basis, such that total customer spend per trading week (Sunday-Saturday) is identified. The week is considered to be an appropriate unit of analysis, with all data available from our collaborating retailer being organized by trading week. The week also forms a common unit of time for self-catering family holidays, which are predominantly bookable on a weekly basis.

Table 2 demonstrates that the spatial origin of trade appears to have a clear impact on consumers' average weekly expenditure. At Coastal Resort Store X, visitors are found to spend less than local residents, with a similar pattern observed at nearby Non-Coastal Store B. However, visitors do spend more than local residents in Coastal Resort Store Y and in Non-Coastal Store A, suggesting that the pattern is complex and varies by both store and destination. It is hypothesized that these variations in relative visitor and residential spend at each store may be explained by systematic differences between the characteristics of the locations and their visitors and local residents, as explored fully in the following sections. Any such differences would cast doubt on the suitability of revenue estimation based simply on a multiplication of residential demand. 
Table 2. Average weekly spend by overnight visitors, shown relative to local residents' spend on a store-by-store basis.

\begin{tabular}{|c|c|c|c|c|}
\hline $\begin{array}{l}\text { Average customer } \\
\text { weekly spend }\end{array}$ & $\begin{array}{l}\text { Coastal Resort } \\
\text { Store X }\end{array}$ & $\begin{array}{l}\text { Coastal Resort } \\
\text { Store Y }\end{array}$ & $\begin{array}{c}\text { Non-Coastal } \\
\text { Store A }\end{array}$ & $\begin{array}{c}\text { Non-Coastal } \\
\text { Store B }\end{array}$ \\
\hline Residents (\%) & 100 & 10 & 10 & 100 \\
\hline Overnight visitors (\%) & 86.5 & 118.2 & 122.3 & 96.1 \\
\hline
\end{tabular}

We begin by considering the social profile of visitors to this area in comparison to the visitors recorded within our loyalty card data, using the National Readership Survey (NRS) (NRS, 2012a) social grade classification.

\section{Segmentation of overnight visitors by social grade}

The social grade classification originating from the NRS has become an established generic classification scheme for social class and is commonly used within surveys of tourism (Williams, 2008). The classification categorizes households into one of six commonly recognized 'grades' ranging from 'higher professional' (A) through to 'on state benefit or unemployed' (E) (see Table 3), based primarily on the occupation of the chief household income owner. The Market Research Society (MRS) (2004) notes that the classification may also be based on a range of other characteristics and thus can be accurately determined only by trained market research interviewers, and not from demographic statistics (Meier and Moy, 2004). Consequently, social grade does not form part of the National Statistics Socio-Economic Classification (NS-SEC). Nonetheless, the 2001 census results contain household level 'approximate social grade' (at an OA level), derived solely from the demographic and socio-economic variables in the census, which is considered to be at an acceptable level of accuracy to represent the true social grade for each household (Meier and Moy, 2004).

Social grade has been assigned to each customer based on their loyalty card home postcode, using the 'approximated social grade' from the 2001 Census Area Statistics. ${ }^{1}$ This enables us to draw observations about the social profiles of visitors that shop in our study stores compared with the profile of visitors to these destinations as reported by a headline tourism survey.

Figure 2(i) outlines the profile of visitors to this area based on the 2010 United Kingdom Tourism Survey (UKTS). The UKTS is a sample survey of around 100,000 respondents per year in which participants are asked to recall

Table 3. Social grade classification.

\section{Social grade(s) Description}

\begin{tabular}{ll}
$\mathrm{AB}$ & Higher and intermediate managerial/administrative/professional \\
$\mathrm{C} 1$ & Supervisory, Clerical, Junior managerial/administrative/professional \\
$\mathrm{C} 2$ & Skilled manual workers \\
$\mathrm{DE}$ & Semi-skilled and unskilled manual workers, on state benefit or unemployed \\
\hline
\end{tabular}

Source: Census Area Statistics Table UVO50. 
(i)

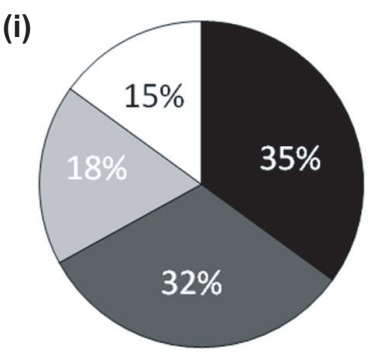

(iii)

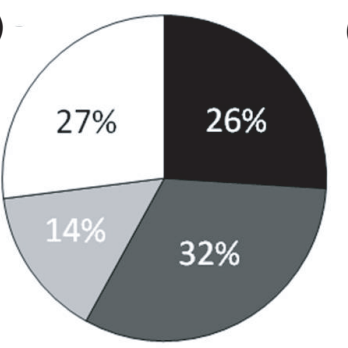

(ii)
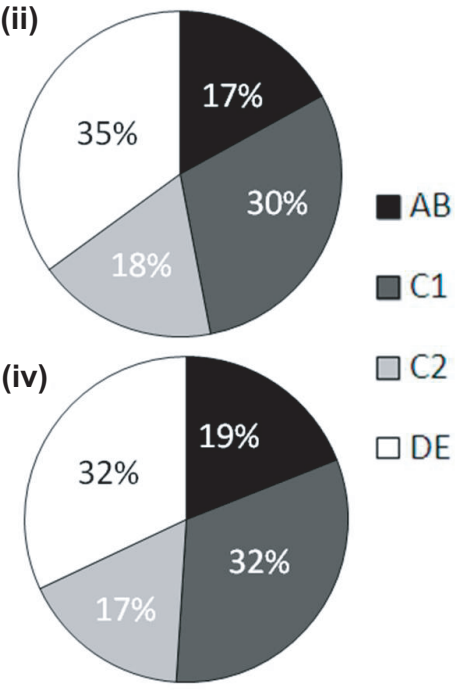

Figure 2. Trade by social grade: (i) UKTS proportion of visitor nights, South West England (2010); (ii) local residents, Cornwall (2001 Census); (iii) overnight visitors from our loyalty card dataset (2010); and (iv) local residents from our loyalty card dataset (2010).

characteristics of up to 3 recent domestic overnight trips (TNS, 2010; Visit England, 2010). UKTS data are weighted to account for the demographic, socioeconomic and geographical characteristics of the population as a whole and can be analysed at a regional level. Figure 2(i) shows the social grade of visitors (proportion of visitor nights by social grade of respondent) to the South West (including Cornwall, Devon, Somerset and Avon, Dorset, and Wiltshire) in 2010.

The UKTS highlights that visitors to this region as a whole fall predominantly $(67 \%)$ into the more affluent $\mathrm{ABC} 1$ groups, whereas nationally only $55 \%$ of households fall into ABC1 groups (NRS, 2012b). By contrast, 2001 census data suggests that $35 \%$ of residents in these store catchments originate from less affluent social grades D and E (Figure 2(ii)). This corresponds very closely to the profile of local residents recorded in-store using our loyalty card data, which suggests that the sample of loyalty card data used is able to accurately represent the profile of customers recorded in-store.

Figure 2(iii) shows the profile of overnight staying visitors recorded in the loyalty card data at our four stores in 2010. This demonstrates somewhat more coherence with the UKTS social profile of visitors to the South West (Figure 2(i)), with $58 \%$ of our overnight staying visitors originating from $\mathrm{ABC} 1$ social groups. Nonetheless, the loyalty card data reveal that $27 \%$ of the overnight staying visitors are inferred to originate from the least affluent social groups $\mathrm{D}$ and $\mathrm{E}$, which is far higher than local or regional visitor surveys would suggest. Furthermore, there are slight variations between the profile of visitors (Figure 2(iii)) and local residents (Figure 2(iv)) recorded in the loyalty card data for the four stores. In particular, overnight visitors display a slightly higher likelihood of originating from more affluent $\mathrm{ABC} 1$ social grades when compared to local residents. 
Further analysis compared the profile of customers at individual stores with the surveyed profile of visitors to specific destinations. At the destination level, for a given resort on the North Coast of Cornwall, the overnight visitors using Coastal Resort Store X displayed a social profile that varied dramatically from the surveyed profile of visitors to the resort, particularly at the $\mathrm{ABC} 1$ level. Furthermore, the overnight visitor trade recorded at our study stores does not match the typical profile of customers at our retailers' stores across the UK, suggesting that stores in tourist resorts may attract a very different profile of customer from their retailers' typical consumer.

This section has highlighted a number of important factors to consider when attempting to understand the nature and composition of visitor demand for use in store location planning. Most notable is the difference between the profile of overnight visitors recorded in-store and the expected profile of overnight visitors based on local visitor surveys. The local visitor surveys (especially at the resort level) suggest that a greater proportion of visitors from $\mathrm{ABC} 1$ social grades shop in-store than would be expected, while compared to the regional UKTS data this proportion is underestimated. In part this may reflect the fact that some social groups may be less likely to shop with, or hold a loyalty card for, our retailer (see Mintel (2011) for the 'typical' customer profile for the major grocery retailers). Nonetheless, this analysis suggests that the composition of visitor trade is driven by a complex range of factors that may not be accurately represented in regional, county-wide or destination-specific visitor surveys. We now make further use of the loyalty card data to understand more about the profile of visitors recorded in these stores, drawing comparisons with local residents and visitors' usual home consumption.

\section{Spend by geodemographic status}

In order to explore variations in the characteristics of visitors and local residents fully, the output area classification (OAC) part of the National Statistics Area Classification was used. The classification is based on 2001 census data and classifies all 175,434 OAs in England and Wales into one of 21 groups based on 41 census variables (Vickers and Rees, 2006). The variables used for the classification reflect the socio-economic nature of the households that make up each OA and include demographic, housing and employment characteristics. Thompson et al (2012) also note that the OAC classification is the only geodemographic classification accredited as a national statistic and thus represents an invaluable tool for identifying key small-area characteristics from the 2001 census and to identify consumption habits associated with different types of household. The Living Costs and Food Survey (LCF) (ONS, 2010) is also reported by OAC group, which forms an important link to surveyed household expenditure data used elsewhere within this research. The OAC categorizes households into one of seven supergroups, which are further sub-divided into a total of 21 groups. All customers using a loyalty card in our study stores have been assigned to the OAC supergroup for their home neighbourhood, allowing comparison of residential and visitor consumption by geodemographic status. Owing to small sample sizes in some OAC groups, this paper uses the supergroup level only. 
As shown in Figure 3, the geodemographic nature of trade varies markedly between local residents and overnight visitors at the OAC supergroup level. At each store, local resident trade is dominated by households within the 'countryside' supergroup, which is unsurprising given the rural or semi-rural nature of a large proportion of the Cornish store catchments. At Coastal Resort Store $\mathrm{X}$, around $35 \%$ of the residential trade is from the 'countryside' supergroup, and over 50\% at Coastal Resort Store Y and Non-Coastal Stores A and B. 'Typical traits' also accounts for almost $40 \%$ of within-catchment trade at Coastal Resort Store X, and up to 30\% at our other stores. Again this is not surprising given the nature of the store catchments, with many areas of Cornwall representing non-affluent former mining communities. Appendix 1 presents the characteristics of these OAC supergroups, with 'countryside' and 'typical traits' spatially covering a large proportion of UK households, representing much of the rural population and a proportion of the slightly less-affluent urban population. According to the LCF (ONS, 2010), households in these OAC supergroups spend up to $£ 56.80$ per week on food and non-alcoholic drink.

By contrast, overnight visitors are dominated by customers from the more affluent 'prospering suburbs' supergroup, accounting for around 30\% of the overnight visitor trade at our study stores. Visitor spend is, however, more evenly distributed across the seven OAC supergroups than residential spend. The dominant overnight visitor therefore tends to be slightly more affluent than the residential trade, with a noticeably higher gross average income, and slightly higher average weekly expenditure on food and drink at $£ 60.10$ per household (LCF) (ONS, 2010). However, this supergroup also has one of the highest expenditures on restaurants and hotels at an average of $£ 47.00$ per week, which may reduce this group's propensity to purchase groceries while away from home, as they may be more likely to use serviced forms of accommodation and to eat out.

The pattern becomes more complex when recorded loyalty card spend is considered in relation to spend by residents from the same OAC supergroup, outlined in Figure 4. Here, visitor spend is shown as a proportion of residential spend in the corresponding store by residents from the same OAC supergroup. A value of 100 identifies that visitor and residential spend are identical, with values over 100 demonstrating that visitors from the given OAC supergroup spend more (on an average weekly basis) than local residents from the same OAC supergroup. In common with Table 2 , it is immediately apparent, that across all OAC supergroups, visitors spend more than residents at Coastal Resort Store Y and Non-Coastal Store A, even when they have similar characteristics. This is particularly true for visitors from the 'city living' supergroup who are found to exhibit an average weekly spend of more than twice that of similar local residents in Non-Coastal Store A (although a small sample size for visitors in this supergroup should be noted).

We have explored the impact of these differences in geodemographic status on available consumer expenditure, taking the catchment area of Coastal Resort Store $\mathrm{X}$ as an example. Using the breakdown of residential households by OAC supergroup (at an OA level) and average weekly food and drink expenditure rates by OAC supergroup (taken from the $\mathrm{LCF}^{2}$ ) we have been able to estimate the available weekly grocery spend in this store catchment derived from local residents. We have applied a 30\% demand uplift, which assumes that visitor 


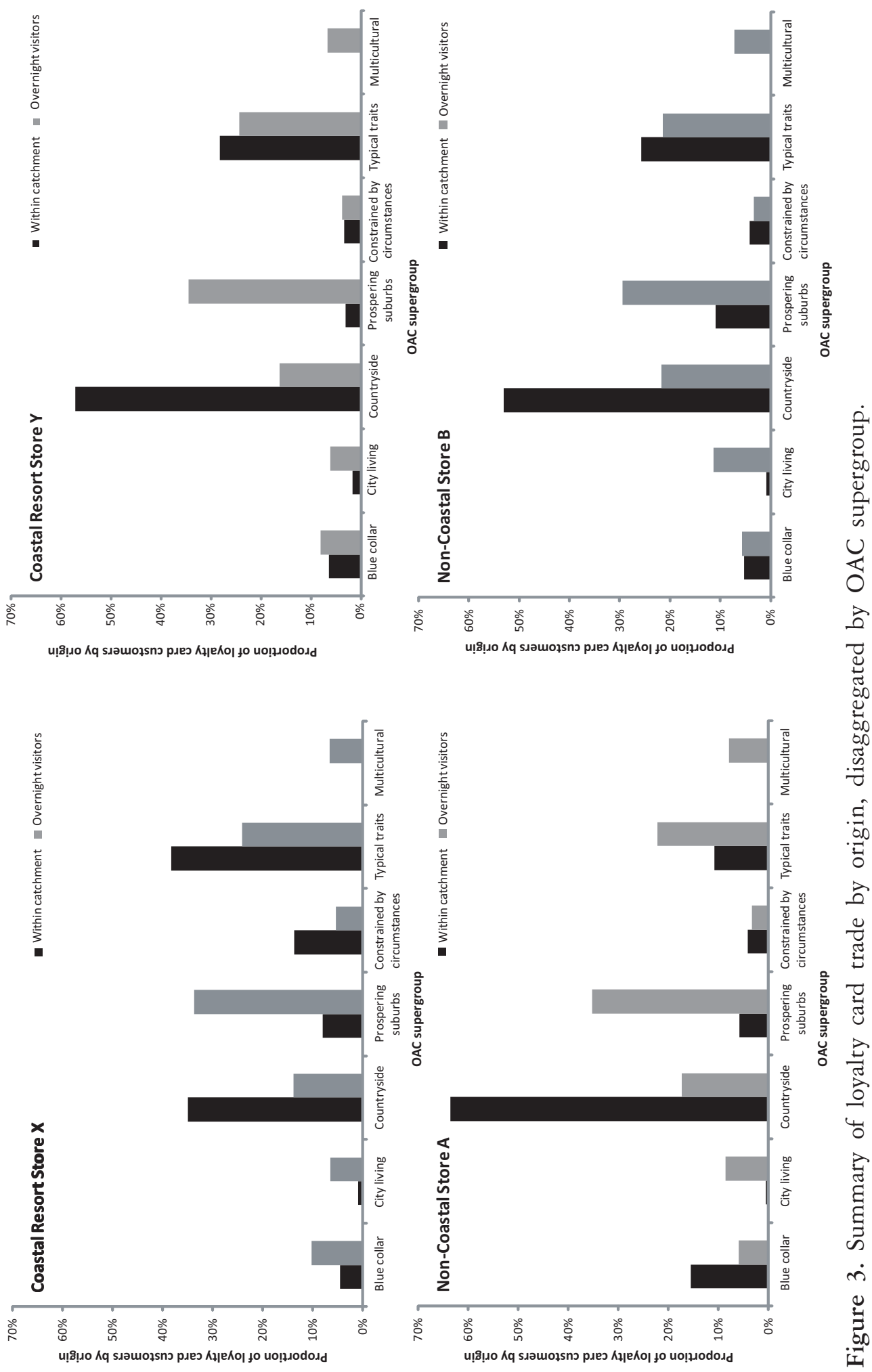




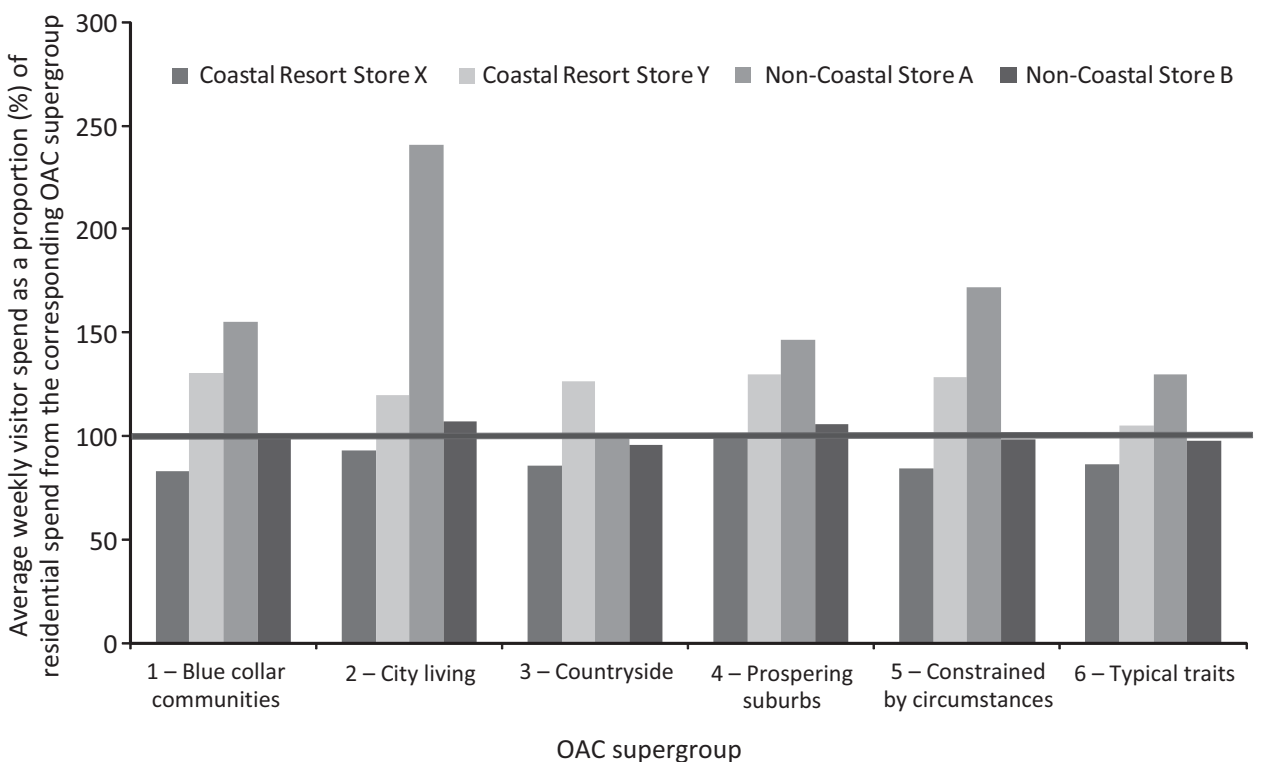

Figure 4. Comparison of visitor and local resident spend by OAC group.

demand exhibits an identical spatial distribution and geodemographic characteristics as residential demand, as is commonly applied by current industry approaches. We have also recalculated the $30 \%$ demand uplift, basing the calculation on the geodemographic characteristics of the visitors recorded at this store (Figure 3), and keeping all other factors consistent. We identify a difference of over $£ 25,000$ in terms of the available weekly grocery spend available within the store catchment area, largely driven by variations in the relative proportions of visitors and residents within the countryside, prospering suburbs and typical traits supergroups.

These findings suggest that some of the variation in average visitor spend between local residents and visitors may result from differences in their geodemographic characteristics, which in turn may lead to different expenditure habits. Therefore, any revenue estimation that attempts to account for visitor spend by factoring up residential spend is unlikely to be able to account for these differences. As such, revenue estimation in these areas should be based on the characteristics of these visitors themselves, and not simply inferred from residential demand, as discussed fully in below. We will now consider the extent to which consumers' regular shopping habits are linked to their expenditure while visiting Cornwall.

\section{Analysis of visitors regular consumption habits}

The loyalty card data also allow visitor consumption recorded in our study stores to be considered in the context of these consumers' broader grocery consumption habits. This section makes use of additional customer level data available from the loyalty card scheme to consider how visitor spend in our study stores varies from these visitors' usual home consumption habits in similar stores. We 
also consider the spatial pattern of loyalty card usage in the week immediately before and during a visit to Cornwall in an attempt to understand more about the complex spatial patterns of visitor spend.

All visitors using a loyalty card in our study stores are identified by a unique ID number, allowing all other transactions by these customers to be identified by week and by store on a customer-by-customer basis. Comparisons can therefore be made between consumers' home consumption and their consumption while visiting Cornwall. The term 'home consumption' refers to all other consumption by overnight visitors that shopped in one of our four study stores. Almost 15,000 customers are used for this comparison, yet it must be acknowledged that this dataset represents only a subset of all visitors to the stores and destinations, and care must be taken when considering the findings. This dataset considers only those customers holding and using a loyalty card issued by this retailer, so customers who frequently shop with this retailer at home but who do not use their loyalty card while away, will not be included in the comparison of home and destination expenditure. Consequently, the dataset may not reveal the full extent of consumers' home shopping habits, but it does provide a unique insight into visitor expenditure habits.

Table 4 provides a comparison of average weekly spend for our loyalty card visitors while in Cornwall and expenditure by the same customers while at home. We account for differences in store size, which could have an impact on consumer spend, since it is unrealistic to compare expenditure within a hypermarket with a neighbourhood store. Visitor expenditure in our four stores is only compared to consumers' home expenditure within other similarly sized stores (based on our retailers' in-house classification of their store portfolio). Likewise, consumers' 'home' expenditure during the Christmas period has also been excluded from the analysis, since consumers tend to exhibit higher spend during this period.

Visitors' average weekly spend in Coastal Resort Store X is around 20\% lower than their regular home spend with this retailer. This suggests that many visitors may be using this resort-centre store for smaller top-up shopping trips, using other local stores or sources to purchase additional food in line with their usual home consumption habits. By contrast, overnight visitors using the smaller Coastal Resort Store Y tend to spend almost 60\% more per week than in similar size stores while at home. This may be because stores of this size

Table 4. Overnight visitors' spend while in Cornwall and at home.

\begin{tabular}{lcc}
\hline & \multicolumn{2}{c}{$\begin{array}{c}\text { Average customer spend per week } \\
\text { Average spend in } \\
\text { Spend as an overnight } \\
\text { visitor in Cornwall (\%) }\end{array}$} \\
$\begin{array}{lcc}\text { 'home' stores (\%) } \\
\text { Coastal Resort Store X }\end{array}$ & 80.9 & 100 \\
Coastal Resort Store Y & 161.2 & 100 \\
Non-Coastal Store A & 92.0 & 100 \\
Non-Coastal Store B & 103.2 & 100 \\
\hline
\end{tabular}

Note: ${ }^{a}$ This is calculated across the number of weeks that this customer actually shopped in the store, not across the entire study period. 
and nature are commonly used for top-up shopping at home, whereas while holidaying in the resort many visitors appear to be using this store for a larger shopping trip with a higher spend, perhaps purchasing items that they would not usually purchase at home, or using this smaller store to save travelling to larger stores in this part of Cornwall. The pattern is however complex, and when considering customers in isolation, there are few clear patterns. With an $R^{2}$ value of just 0.05 , consumer's average weekly expenditure at home has virtually no relationship with their recorded expenditure while in Cornwall. Consequently, an understanding of how consumers shop at home during their regular trips to our retailer is not necessarily an indicator of their likely purchasing habits in-store while away from home.

We have also hypothesized that visitors staying in Cornwall may bring some food and drink supplies from home, shop en route to their destination or exhibit complex patterns of mobility once in the destination, perhaps shopping in multiple stores linked to day trips and visits to attractions some distance from their accommodation. The loyalty card data afford some potential when investigating the spatial patterns of visitor expenditure during and immediately prior to their trip. Overnight visitors that shopped at Coastal Resort Store $\mathrm{X}$ are used here, since it has already been suggested that visitors using this store are likely to be purchasing food and drink from additional stores or sources (because of the relatively low spend in comparison to residents). Taking all overnight visitors that had shopped in Coastal Resort Store X during the school summer holidays (August, 2010), we identified all transactions carried out using their loyalty card during the week of their visit and during the week immediately prior to their trip, recording the store and spend for each transaction.

Table 5 outlines the expenditure profiles of three overnight visitors who shopped in Coastal Resort Store X. These customers are fairly typical of the range of consumption habits identified, highlighting the complex range of trip related expenditure habits. Customer A, for example, exhibits a far higher spend than usual during their pre-trip shop, which is carried out at home, toppingup twice more while in the destination (using Coastal Resort Store X and NonCoastal Store B). Clearly, as hypothesized previously, this customer spends considerably more during their trip than during their regular consumption and splits this expenditure between stores at home and in the destination. Approximately $40 \%$ of our customer sample exhibit habits that are broadly similar, although the exact volume and value of sales varies considerably.

Customer B carries out their pre-trip shop en route to the destination, shopping in a store close to the M5 motorway, again spending more than in their regular shopping trips with this retailer. In common with Customer A, Customer B also splits their in-destination spend across multiple stores and similar characteristics are exhibited by around $35 \%$ of our sample. By contrast, Customer $\mathrm{C}$ is a low-spender in the destination and actually spends slightly less than usual during their pre-trip shop, recording no other transactions during the week of their trip. This customer may therefore have used serviced accommodation, or been hosted by friends and relatives, resulting in a low food spend. They may also demonstrate little brand loyalty while away from home, shopping with other retailers en-route or while in the destination.

Table 5 illustrates the range of complex individual-level expenditure profiles exhibited by visitors that used our study stores. At the aggregate level, much 


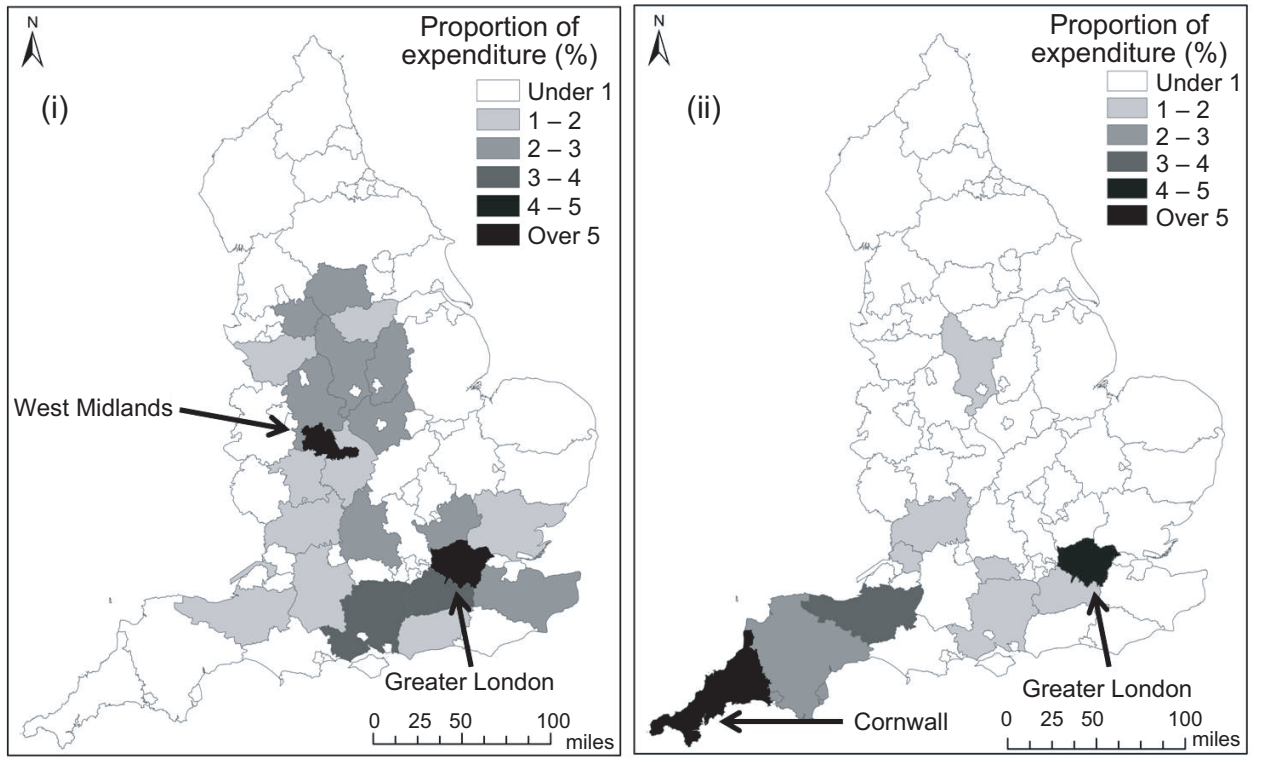

Figure 5. (i) Spatial origin and (ii) store location (excluding home stores) for overnight visitor trip related expenditure, by county.

Source: Based on a sample of overnight visitors using Coastal Resort Store X during summer 2010.

of this individual level stochastic behaviour is overlooked. Nonetheless, observations about the spatial patterns of visitor spend can still be made. Figure 5 shows all additional trip-related expenditure within our retailers' stores, carried out by our sample of customers during the week prior to their trip and during the week of their trip itself. In Figure 5(i), this expenditure is shown by their point of residence and highlights that visitors originate from a range of areas across England, but particularly Greater London and the West Midlands. Figure 5(ii) considers the same expenditure, but records the location of the stores in which the spending took place. Figure 5(ii) highlights that trip related expenditure (aggregated at a county level) is displaced from visitor home locations to a range of alternative stores used for shopping en route to or in the destination.

Figure 5 therefore presents very clear evidence, in common with Table 5 , that a proportion of visitors carry out a major food shop en route to Cornwall or at other stores located in Cornwall during their trip. In particular Non-Coastal Stores A and B and another large store within Cornwall, plus a large store located close to the M5 motorway, attract large shares of additional trip-related spend originating from customers that we recorded as overnight visitors using Coastal Resort Store X. Visitors also appear to be highly mobile once within a destination such as Cornwall, visiting multiple stores in a variety of resorts. The pattern remains complex, however, and the loyalty card data reveal that many of these visitors routinely record transactions in a number of additional stores some distance from their home address. This form of mobility must be considered when attempting to model flows of visitor spend in destinations such as Cornwall, as discussed below. 


\section{Discussion and conclusion}

This paper sought to explore visitor expenditure on groceries at an individual consumer level using selected stores and resorts in Cornwall. The loyalty card dataset has allowed visitor expenditure to be analysed by key socio-economic and demographic characteristics using the OAC classification and a comparison has also been drawn with headline visitor surveys using inferred social grade. Visitor expenditure has also been compared to residential expenditure in the study resorts and to visitors' usual home consumption habits at both the aggregate and individual level.

The geodemographic characteristics of consumers at these stores clearly vary by spatial origin, with overnight visitors having a higher propensity to originate from a home postcode in more affluent and higher spending OAC groups. However, at some stores, local residents tend to have a higher average weekly spend than visitors, even where their geodemographic characteristics are similar. This may suggest that visitors are using the stores differently to locals, perhaps purchasing less and instead substituting with food and drink purchased in cafes, bars and restaurants, provided as part of their accommodation, or food that they have brought with them from home. At other stores such as Coastal Resort Store $\mathrm{Y}$, visitors spent, on an average weekly basis, $20 \%$ more than locals in the same store, and more than they would do in a similar store at home. Coastal Resort Store $\mathrm{Y}$ therefore appears to be an important part of the service provision for visitors, supporting larger shopping trips than would be expected perhaps due to its location in the centre of a major resort, close to other attractions, while locals may be more likely to travel outside the resort to shop elsewhere.

Non-Coastal Store A, located on a principal transport route, also appears to be an important source of food and drink for many visitors, with visitors spending more than locals with similar characteristics, while Non-Coastal Store $\mathrm{B}$ also tends to be used by visitors that have shopped in Coastal Resort Store $\mathrm{X}$, suggesting that these stores' location makes them popular choices for visitors, and thus services provided some distance from principal resorts themselves may still benefit from seasonal visitor expenditure. This may also suggest that visitors are highly mobile, carrying out grocery shopping while visiting attractions or other destinations, even though they may be staying elsewhere in the county. Furthermore, visitors may display less brand loyalty while away from home, with the social profile of overnight visitors recorded in-store not matching our retailers' usual customer profile, or the profile of visitors expected based on headline tourism surveys for this destination. By failing to accurately account for visitor demand within the store location planning approaches, retailers may increasingly identify that stores lack the capacity to meet the needs of local residents and visitors at certain times of year (consider, for example, Tesco in Padstow, outlined above).

We therefore argue that it is impossible to obtain meaningful revenue estimations that incorporate visitor spend by simply factoring up estimates that are based on residential demand. Instead we suggest that any business model for local service provision in tourist resorts should consider:

- the precise spatial distribution of visitors, which tend to be clustered around key accommodation sites and specific resorts far more than residential demand and which could be modelled at the small-area level in such a model; 
- observed differences between the geodemographic and socio-economic characteristics of visitors and local residents, with each group being treated separately in the model;

- observed variations in the expenditure habits of visitors relative to local residents, which can again be handled separately in such a model; and

- inferred variations in the relative attractiveness of individual stores to residents and visitors.

The creation and validation of such a model for this context represents ongoing work by the authors and will be reported subsequently. Unlike the traditional factoring approach, the use of more sophisticated modelling requires greater data input, most notably estimates of small-area visitor demand for use in that model. These estimates will be generated for various times in the peak, fringe and low seasons and will be driven by the small area provision of visitor accommodation, and represent the next stage of this research. This insight into the impact of seasonal variations in small area visitor numbers and associated demand has important implications far beyond the estimation of food and drink expenditure. A range of businesses, services and other organizations in tourist resorts experience seasonal demand fluctuations resulting from varying visitor numbers or characteristics. For example, the NHS (UK National Health Service) struggles to meet demand uplift for services driven by an influx of visitors at certain times of year (Cornwall Single Issue Panel, 2004) and would benefit from greater knowledge of small area visitor numbers and the geodemographic characteristics of overnight visitors at different times in the season. While this study seeks explicitly to estimate seasonal variations in grocery demand, ${ }^{3}$ the comparisons drawn between local residents and visitors, and the methodologies that will be subsequently developed to estimate small area visitor numbers and associated demand could indeed be applied to other sectors or services that experience seasonal demand fluctuations driven by tourism in Cornwall or other coastal/rural destinations.

We conclude that visitor expenditure of this nature is complex and appears to vary by destination and type of customer. We strongly assert that at a store or local level the impact of visitor expenditure cannot be accounted for by simply factoring local residential demand because of differences in visitors' geodemographic and socio-economic characteristics. This paper has highlighted a number of important considerations for store location planning and for the analysis of tourism's local economic impact. In particular, an aggregate level focus solely on seasonal trading variations hides the complexity of seasonal sales variations driven by individual consumer expenditure and suggests that traditional approaches to estimate local-level impact fail to account for the nature of visitor demand.

\section{Endnotes}

1. Table UV050

2. Formerly the Expenditure and Food Survey, which itself succeeded the Family Expenditure Survey and the National Food Survey. Reported via an annual report titled 'Family Spending' and often referred to by this name.

3. Due to the nature of the ESRC funding and commercial partner that is supporting this work via the Retail Industry Business Engagement Network (RIBEN) (see http://www.riben.org.uk/). 


\section{References}

Algere, J., and Magdalena, C. (2010), 'Tourist expenditure and quality: why repeat tourists can spend less than first-timers', Tourism Economics, Vol 16, pp 517-533.

API (2010), Retail Assessment: Existing Tesco Store, West Hill, Wadebridge, Amethist Property Investments Limited, Bristol.

API (2011), Retail Assessment: Proposed Foodstore, Land off Victoria Road, Camelford, Amethist Property Investments Limited, Bristol.

API (2012), Retail Assessment: Proposed Foodstore, Land off Barbican Road Looe, Amethist Property Investments Limited, Bristol.

Barquet, A., Brida, J.G., Osti, L., and Schubert, S. (2011), 'An analysis of tourists' expenditure on winter sports events through the Tobit censorate model', Tourism Economics, Vol 17, No 6, pp 1197-1217.

Bracalente, B., Chirieleison, C., Cossignani, M., Ferrucci, L., Gigliotti, M., and Ranalli, M.G. (2011), 'The economic impact of cultural events: the Umbria Jazz music festival', Tourism Economics, Vol 17, No 6, pp 1235-1255.

Cornwall Single Issue Panel (2004), The Impact of Tourism on Health Services in Cornwall, Cornwall Single Issue Panel (now part of Cornwall Council), Truro.

Craggs, R., and Schofield, P. (2009), 'Expenditure-based segmentation and visitor profiling at The Quays in Salford, UK', Tourism Economics, Vol 15, pp 243-260.

Downward, P., and Lumsdon, L. (2000), 'The demand for day-visits: an analysis of visitor spending', Tourism Economics, Vol 6, pp 251-261.

Downward, P., and Lumsdon, L. (2003), 'Beyond the demand for day-visits: an analysis of visitor spending', Tourism Economics, Vol 9, pp 67-76.

Dudding, V., and Ryan, C. (2000), 'The impacts of tourism on a rural retail sector: a new Zealand case study', Tourism Economics, Vol 6, pp 301-319.

Huse, M., Gustavsen, T., and Almedal, S. (1998), 'Tourism impact comparisons among Norweigan towns', Annals of Tourism Research, Vol 25, No 3, pp 721-738.

Jones, C., and Munday, M. (2009), Understanding Tourism's Economic Impact, Welsh Economy Research Unit, University of Cardiff, Cardiff.

Maguire, M. (2010), Application for Planning Permission Submitted to Cornwall Council: Erection of a Temporary Extension to Tesco store, Padstow. Ref: 2010/00221, Finch Associates, Carnoustie.

Meier, E., and Moy, C. (2004), 'Social grading and the census', International Journal of Market Research, Vol 46, No 2, pp 141-170.

Mintel (2011), 'Food retailing (UK)' (http://academic.mintel.com/sinatra/oxygen_academic/my_reports/ display/id=545201\&anchor=atom\#atom0, accessed 26 November 2011).

MRS (2004), 'MRS social grade approximation for the 2001 census' (http://www.mrs.org.uk/networking/cgg/cggsocialgrade.htm, accessed 17 October 2011).

Natural England (2005), England Leisure Visits: Report of the 2005 Survey, Natural England, Wetherby.

Newing, A., Clarke, G., and Clarke, M. (2012), 'Identifying seasonal variations in store-level visitor grocery demand', working paper, School of Geography, University of Leeds. Copy available from the author on request.

NRS (2012a), National Readership Survey, National Readership Surveys Ltd, London.

NRS (2012b), 'Social grade - definitions and discriminatory power' (http://www.nrs.co.uk/lifestyle. html, accessed 20 June 2012).

ONS (2010), Family Spending: A Report on the 2009 Living Costs and Food Survey, Office for National Statistics, Newport.

South West Tourism (2010), Value of Tourism 2008: Cornwall, South West Tourism, Exeter.

Thompson, C., Clarke, G., Clarke, M., and Stillwell, J. (2012), 'Modelling the future opportunities for deep discount food retailing in the UK', International Review of Retail, Distribution and Consumer Research, Vol 22, No 2, pp 143-170.

Timothy, D. (2005), Shopping Tourism, Retailing and Leisure Aspects of Tourism, Channel View Publications, Clevedon.

TNS (2010), 193058. United Kingdom Tourism Survey 2009 Methods and Performance Report, TNS Research International, Edinburgh.

Vickers, D., and Rees, P. (2006), 'Introducing the area classification of output areas', Population Trends, Vol 125, pp 15-29.

Visit Britain (2010), 'UK tourism survey proves reality of staycationing' (http://www.accommodation knowhow.co.uk/new-this-month/news/uk-tourism-survey-proves-reality-of-staycationing, 15 December 2010). 
Visit Cornwall (2010), Cornwall Named Top UK Holiday Destination in British Travel Awards for Second Consecutive Year (Media Release), Visit Cornwall, Truro.

Visit England (2010), 'The United Kingdom tourism survey (UKTS) - about the survey' (http:// www.visitengland.org/insight-statistics/major-tourism-surveys/overnightvisitors/MoreAboutthe Survey/More_About_the_Survey.aspx, 15 December 2010).

Williams, P. (2008), 'Segmenting the tourism' (http://www.insights.org.uk, accessed 15 May 2012).

Williams, S., and Botterill, A. (2006), 'Profiling areas using the output area classification', Regional Trends, Vol 39, pp 11-18.

Wilton, D. (2004), Long Term Trends and Cycles in Canadian Tourism, Canadian Tourism Commission Ottawa.

Young, R., Young, A., Parkin, J., and Diamond, A. (2010), 'Assessing the economic impact of culture in English market towns: a causal chain approach', Tourism Economics, Vol 16, pp 925951. 


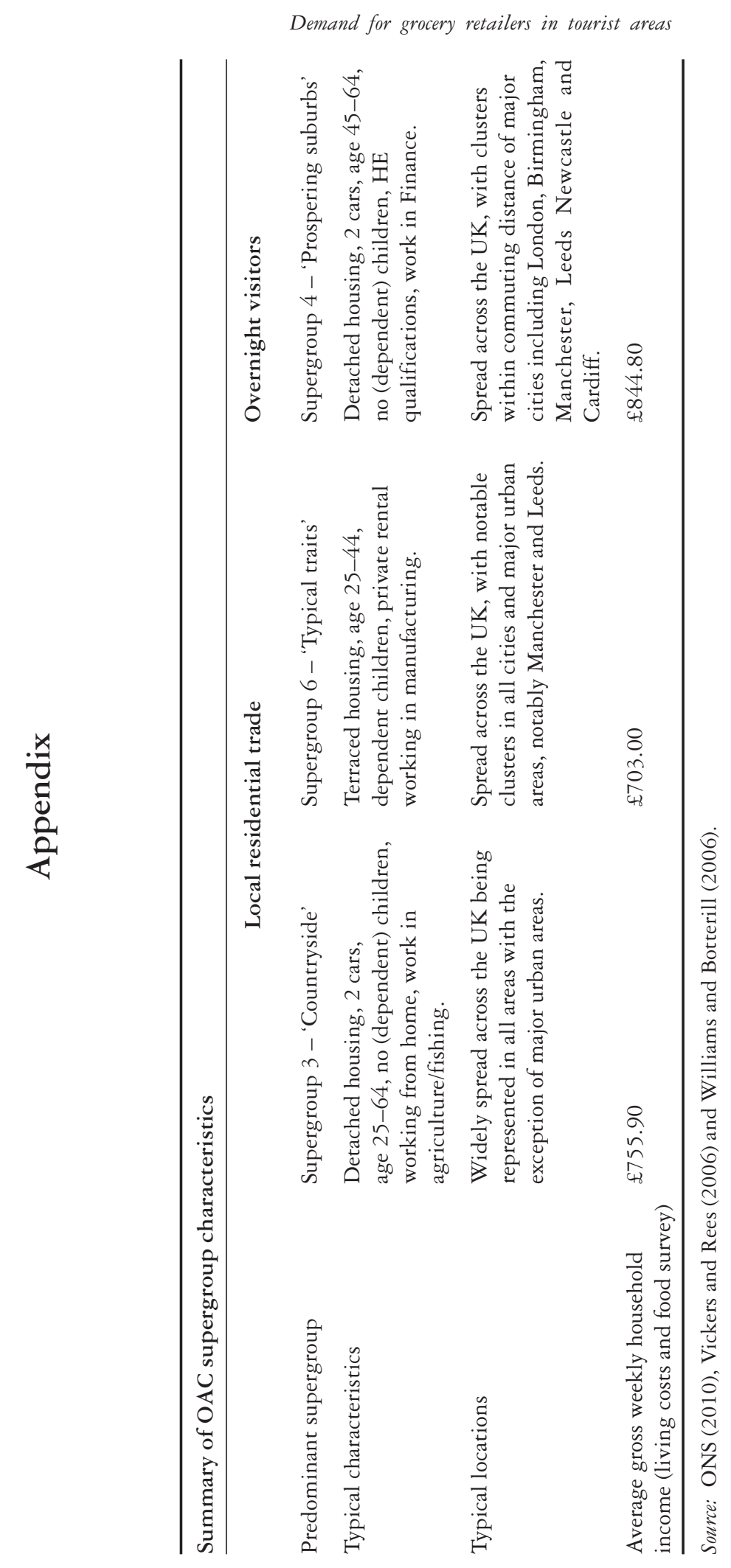

